\title{
Correction: CXC chemokine ligand 12/Stromal cell-derived factor-1 regulates cell adhesion in human colon cancer cells by induction of intercellular adhesion molecule-1
}

Shui-Yi Tung ${ }^{1,2^{*}}$, Shun-Fu Chang ${ }^{3}$, Ming-Hui Chou ${ }^{4}$, Wen-Shih Huang ${ }^{5}$, Yung-Yu Hsieh ${ }^{1}$, Chien-Heng Shen ${ }^{1}$, Hsing-Chun $\mathrm{Kuo}^{6}$ and Cheng-Nan Chen ${ }^{4}$

\section{Correction}

After publication of this work [1], we noted that we inadvertently failed to add the affiliations of first author Shui-Yi Tung. The author has now been added.

\section{Competing interests}

The authors declare that they have no competing interests.

\section{Authors' contributions \\ S-YT and C-NC designed research; S-YT, S-FC, M-HC, W-SH, Y-YH, and C-HS performed research; S-YT, S-FC and C-NC analyzed data; and H-CK and C-NC wrote the paper. All authors read and approved the final manuscript.

\begin{abstract}
Author details
'Department of Hepato-Gastroenterology, Chang Gung Memorial Hospital, Chiayi, Taiwan. ${ }^{2}$ Chang Gung University College of Medicine, Taoyuan, Taiwan. ${ }^{3}$ Biophotonics \& Molecular Imaging Research Center, National Yang Ming University, Taipei, Taiwan. ${ }^{4}$ Department of Biochemical Science and Technology, National Chiayi University, Chiayi, Taiwan. ${ }^{5}$ Division of Colon and Rectal Surgery, Department of Surgery, Chang Gung Memorial Hospital, Chiayi, Taiwan. ${ }^{6}$ Department of Nursing, Chang Gung University of Science and Technology; Chronic Diseases and Health Promotion Research Center, CGUST, Chiayi, Taiwan.
\end{abstract}

Received: 25 March 2013 Accepted: 26 March 2013

Published: 26 March 2013

\section{References}

1. Tung SY, Chang SF, Chou MH, Huang WS, Hsieh YY, Shen CH, Kuo HC,

Chen CN: CXC chemokine ligand 12/stromal cell-derived factor-1 regulates cell adhesion in human colon cancer cells by induction of intercellular adhesion molecule-1. J Biomed Sci 2012, 19:91.

\section{doi:10.1186/1423-0127-20-21}

Cite this article as: Tung et al:: Correction: CXC chemokine ligand 12/ Stromal cell-derived factor-1 regulates cell adhesion in human colon cancer cells by induction of intercellular adhesion molecule-1. Journal of Biomedical Science 2013 20:21.

\footnotetext{
* Correspondence: ma1898@adm.cgmh.org.tw

${ }^{1}$ Department of Hepato-Gastroenterology, Chang Gung Memorial Hospital, Chiayi, Taiwan

${ }^{2}$ Chang Gung University College of Medicine, Taoyuan, Taiwan
}

\section{Biomed Central}

(c) 2013 Tung et al.; licensee BioMed Central Ltd. This is an Open Access article distributed under the terms of the Creative Commons Attribution License (http://creativecommons.org/licenses/by/2.0), which permits unrestricted use, distribution, and reproduction in any medium, provided the original work is properly cited. 